\title{
Improved derivatization of malondialdehyde with 2-thiobarbituric acid for evaluation of oxidative stress in selected tissues of chickens
}

\author{
P. Konieczka, A.J. Rozbicka-Wieczorek, E. Więsyk, S. Smulikowska and M. Czauderna ${ }^{1}$ \\ The Kielanowski Institute of Animal Physiology and Nutrition, Polish Academy of Sciences, 05-110 Jabłonna, Poland
}

KEY WORDS: malondialdehyde, 2-thiobarbituric acid, ultra-fast liquid chromatography, biological materials, oxidative stress, chickens

Received: 7 November 2013

Revised: 14 January 2014

Accepted: 12 June 2014

${ }^{1}$ Corresponding author:

e-mail: m.czauderna@ifzz.pan.pl

\begin{abstract}
A selective and sensitive method based on derivatization with 2-thiobarbituric acid and ultra-fast liquid chromatographic separation is described for the determination of malondialdehyde (MDA) in chicken liver, muscles and adipose tissue, and in lard and fish oil. Preparation of samples involves acid hydrolysis and derivatization. Separation is achieved using an Accucore C18-column ( $2.6 \mu \mathrm{m}$, Hydro-RP, $150 \times 3.0 \mathrm{~mm}$ ), an acetonitrile gradient in water, and detection at $530 \mathrm{~nm}$. The results indicate that external calibration based on standard solutions of MDA may be used for measuring the MDA concentration in adipose tissue, lard and fish oil due to the absence of matrix effects. The MDA concentration in protein-rich biological samples should be calculated as the difference between the MDA concentration measured in MDA-spiked and unspiked samples of the same specimen and mass and the known concentration of the MDA spike. For liver or muscle samples, we suggest using external calibration based on standard solutions of MDA added to the same mass of liver or muscles. The proposed method is suitable for rapid and sensitive analysis of MDA in samples of animal origin or in plant oils. The method can also be suitable for routine evaluation of oxidative stress in animal tissues and oxidative stability of biological materials and animal products.
\end{abstract}

\section{Introduction}

Malondialdehyde (MDA) is commonly used in animal models and humans as a non-invasive index of lipid peroxidation induced by oxidative stress (Lykkesfeldt, 2001; Mateos and Bravo, 2007; Grotto et al., 2009). Following peroxidation of polyunsaturated fatty acids (PUFA) in lipids, PUFA peroxides are decomposed into more complex forms and into reactive species such as MDA and 4-hydroxynonenal (4-HNE), natural by-products of lipid peroxidation (Esterbauer et al., 1991; Grotto et al., 2009). Oxidative modification of lipids can be induced in vitro by a wide array of pro-oxidant agents and occurs in vivo during aging, the overproduction of reactive species, and in certain diseases (Oter et al., 2012). Measuring the end products of lipid peroxidation is one of the most widely accepted assays for oxidative damage in living organisms and biological materials. These aldehydic secondary products of lipid peroxidation are generally accepted indexes of oxidative stress (Mateos and Bravo, 
2007; Grotto et al., 2009). Lipid peroxidation can also be evaluated by quantification of ethane and pentane gases, isoprostanes, conjugated dienes, and 4-HNE (Esterbauer et al., 1991; Mateos and Bravo, 2007; Grotto et al., 2009). Another way to measure oxidative damage is by assessing modifications in protein (Levine et al., 1994), DNA (Dizdaroglu et al., 2002; Grotto et al., 2009; Oter et al., 2012) and RNA oxidation (Baldeiras et al., 2010; Kong and Lin, 2010), but these modifications and oxidation products can be formed by pathways other than those that generate free radicals. Therefore, MDA is a better indicator of oxidative damage to cells, tissuesand food forhumans and animals (Lykkesfeldt, 2001; Korchazhkina et al., 2003; Mateos and Bravo, 2007; Grotto et al., 2009; Czauderna et al., 2011). The most common method for determining MDA in biological materials is based on its reaction with 2,4-dinitrophenyl-hydrazine (DNPH) at low $\mathrm{pH}$ with the formation of the DNPH-derivative, which strongly absorbs in the region of 300-380 nm (Korchazhkina et al., 2003; Czauderna et al., 2011). This method has been used to measure MDA in urine and tissues of living organisms and in other biological materials (e.g., food or feed). Employment of liquid chromatography (HPLC) has improved the selectivity of measuring DNPH derivatives in biological materials (Korchazhkina et al., 2003; Czauderna et al., 2011). Unfortunately, this HPLC-assay is based on the DNPH derivative that has an absorbance maximum at $\sim 307 \mathrm{~nm}$ (Korchazhkina et al., 2003; Czauderna et al., 2011). The major disadvantage of detection at $\sim 307 \mathrm{~nm}$ is that many endogenous species in biological samples have a high molar absorption in the region of 260-380 nm, i.e. these species are not transparent at $307 \mathrm{~nm}$ (Korchazhkina et al., 2003; Czauderna et al., 2011). Therefore, it is better to derivatize MDA with reagents possessing high molar absorptivity at longer UV wavelengths (i.e. above $500 \mathrm{~nm}$ ). Considering the above, we developed a new method of measuring MDA in biological materials, based on acid hydrolysis followed by pre-column derivatization with 2-thiobarbituric acid (TBA), which is very sensitive towards MDA (Wong et al., 1987; Nielsen et al., 1997; Hong et al., 2000; Mateos and Bravo, 2007; Grotto et al., 2009). Fortunately, the TBA-derivative of MDA is monitored at a unique wavelength (i.e. at $\sim 531 \mathrm{~nm}$ ), therefore, other endogenous species present in biological materials do not interfere. Therefore, the aim of the current experiment was to develop a procedure involving the preparation of biological materials followed by derivatization of MDA with TBA and then to optimize quantification using ultra-fast liquid chromatography (UFLC) with photodiode detection (DAD). We expect that our improved procedure will allow for more accurate and precise evaluation of oxidative stress and oxidative stability in selected tissues of animals and in animal products, e.g., food, compared with previously used techniques.

\section{Material and methods}

\section{Chemicals}

All reagents were of analytical grade, and the organic solvents were of HPLC-grade. Trichloroacetic acid (TCA) and HPLC-grade acetonitrile were purchased from POCH (Gliwice, Poland), 1,1,3,3-tetramethoxypropane (TMP; an MDA precursor) (99\%) and 2-thiobarbituric acid (TBA; 98\%) were supplied by Sigma (St. Louis, MO, USA). HPLCgrade water was used for the preparation of the mobile phase, and chemical reagents were prepared using an Elix ${ }^{\mathrm{TM}}$ water purification system (Millipore, Toronto, Canada). Water was filtered through a $0.45 \mu \mathrm{m}$ membrane filter (Millipore, Billerica, USA) prior to liquid chromatography.

\section{Reagent preparation}

The TBA solution $(0.668 \%, \mathrm{w} / \mathrm{v})$ was prepared by dissolving $167 \mathrm{mg}$ of TBA in approximately $20 \mathrm{ml}$ of water, with stirring on a hot plate $\left(50^{\circ} \mathrm{C}-55^{\circ} \mathrm{C}\right)$. After cooling to room temperature, the volume was adjusted to $25 \mathrm{ml}$ with water. To prepare the MDA standard solution $(0.588 \mathrm{mM}), 10$ $\mu \mathrm{l}$ of TMP was added to $100 \mathrm{ml}$ of $20 \%$ aqueous $(\mathrm{m} / \mathrm{m})$ TCA solution. This prepared MDA standard solution (I) was stored at $1{ }^{\circ} \mathrm{C}-2^{\circ} \mathrm{C}$ in the dark and freshly prepared on the day of experiment. Fresh adipose tissues, liver, breast muscles and thigh muscles from chickens were homogenized using a tissue homogenizer (type IKA ${ }^{\circledR} \mathrm{T} 18$ basic, Ultra-Turrax ${ }^{\circledR}$, Germany).

\section{Acid hydrolysis of biological samples and derivatization procedure}

Sample hydrolysis was carried out in $15 \mathrm{ml}$ capacity Pyrex ${ }^{\circledR}$ glass tubes with PTFE-lined screw-on lids. Fresh chicken adipose tissue, muscle or liver samples (50-300 mg), fish oil (25-200 mg) and lard (100-300 mg) were homogenized for $1 \mathrm{~min}$ in $2 \mathrm{ml}$ of $20 \%$ TCA. The tubes were then placed in a water bath at $95^{\circ} \mathrm{C}$ for $20 \mathrm{~min}$. It is recommended to protect the obtained mixture from light. At the end of the incubation, saponified samples were cooled $\left(\sim 5^{\circ} \mathrm{C}\right)$ and the resulting mixture was centrifuged at 
about $5100 \mathrm{~g}$ for $15 \mathrm{~min}$ at $14^{\circ} \mathrm{C}$. Afterwards, the obtained supernatant was used for the derivatization procedure as below. To $1 \mathrm{ml}$ of the supernatant, $0.5 \mathrm{ml}$ of the TBA solution was added. The concentration of TCA in the resulting solution was about $13.3 \%(\mathrm{~m} / \mathrm{m})$. The obtained solution was vigorously mixed and reacted for $60 \mathrm{~min}$ at $95^{\circ} \mathrm{C}$. It is recommended to protect the processed solution from light. At the end of the derivatization procedure, the resulting solution was cooled on ice and centrifuged at about $5100 \mathrm{~g}$ for $15 \mathrm{~min}$ at $14^{\circ} \mathrm{C}$. The supernatant was then transferred to a vial and a 5-45 $\mu 1$ sample of the resulting solution was injected onto the column for analysis.

Blank samples were obtained by replacing the biological materials with $1 \mathrm{ml}$ of $20 \%$ TCA.

\section{Derivatization procedure for MDA standards}

The derivatization procedure for MDA standards was similar as for biological materials. Briefly, to $5-100 \mu \mathrm{l}$ of freshly prepared $0.588 \mathrm{mM}$ MDA standard solution (I), 20\% TCA was added to a final volume of $1 \mathrm{ml}$. Next, $0.5 \mathrm{ml}$ of the TBA solution was added. The obtained solution was vigorously mixed and reacted at $95^{\circ} \mathrm{C}$ for $60 \mathrm{~min}$ with continuous shaking. It is recommended to protect the processed solution from light. The resulting solution was then transferred to a vial and a 5-40 $\mu 1$ sample of the derivatized standard solution was injected onto a column for analysis. The calibration equation and correlation coefficient were obtained using derivatized MDA (derived from TMP) in a range from 0.386 to $24.7 \mathrm{ng}$.

The reproducibility of the described method was assessed by performing replicate injections of processed biological materials (intra-assay coefficients of variations; ${ }^{\text {intra }}$ C.V., \%). The inter-assay coefficients of variations $\left({ }^{\text {inter }} \mathrm{C} . \mathrm{V} ., \%\right.$ ) were calculated by using replicate processing aliquots of biological samples.

\section{Chromatographic equipment, conditions and gradient composition}

A liquid chromatographic system (SHIMADZU, Kyoto, Japan), incorporating two liquid chromatographic pumps (UFLCXR), an autosampler (LFLCXR), a column oven, a degasser and a diode array detector (DAD), was used in the current study. The DAD was equipped with a $10 \mu \mathrm{l}$ flow cell and operated in the UV range of 190-620 $\mathrm{nm}$. The measurement frequency was 1 spectrum per sec and spectral resolution was $1.2 \mathrm{~nm}$. Separations were performed on an Accucore C18-column (particle size $2.6 \mu \mathrm{m}$, Hydro-RP, $150 \times 3.0 \mathrm{~mm}$; Thermo-
Scientific, USA) in conjunction with a guard column containing Accucore $\mathrm{C} 18$ pellicular packing material $(2.6 \mu \mathrm{m} ; 10 \times 4 \mathrm{~mm}$; Thermo-Scientific, USA). A column heater maintained the temperature at $45^{\circ} \mathrm{C}$. The samples were analysed using a binary gradient programme of acetonitrile in water; the total flowrate was $1.5 \mathrm{ml} \cdot \min -1$ (Table 1). All changes of solvent compositions were linear. When the acetonitrile concentration increased from $10 \%$ to $90 \%$, the system pressure decreased from 59.8 to $32 \mathrm{MPa}$.

Table 1. Gradient programme used for the analysis of the MDA-TBA adduct in assayed samples

\begin{tabular}{lll}
\hline \multirow{2}{*}{ Time, $\min$} & Composition, $\%$ & \\
\cline { 2 - 3 } water $^{1}$ & acetonitrile \\
\hline 0 & 90 & 10 \\
10 & 65 & 35 \\
30 & 10 & 90 \\
$31^{2}$ & 90 & 10 \\
\hline
\end{tabular}

${ }^{1}$ water was freshly prepared on the day of experiment; ${ }^{2}$ after $31 \mathrm{~min}$; the column was re-equilibrated for 6 min in $90 \%$ water and $10 \%$ acetonitrile at the flow-rate of $1.5 \mathrm{ml} \cdot \mathrm{min}^{-1}$

In order to minimize precipitate formation, the processed standards and all assayed biological material samples were stored at $20^{\circ} \mathrm{C}$ in an autosampler before injection of 5-45 $\mu 1$ of analysed samples onto the column.

The MDA-TBA peaks in biological samples were identified on the absorption spectra by comparing retention times of the MDA-TBA peak in processed MDA standards (derived from TMP) that were injected separately and by adding MDA standard solutions to processed biological samples. The limit of detection (LOD) was calculated at a signalto-noise ratio of $3: 1$, while the limit of quantification (LOQ) was calculated at a signal-to-noise ratio of 10:1 (Czauderna and Kowalczyk, 2001). The average noise level was calculated from heights of noises on both sides of the MDA-TBA peak in ten TMP standard solutions and assayed biological samples (from ten repeated injections).

\section{Analysis of the purity of the MDA-TBA peak in processed biological samples}

The purity $(P u, \%)$ of the MDA-TBA peak was determined using our previously described method (Czauderna and Kowalczyk, 2001; Czauderna et al., 2011). Moreover, the purity of the MDA-TBA peak in the TMP standards and all assayed biological samples was determined using SHIMADZU LC workstation 'LCsolution' software (SHIMADZU 2008; Japan). 


\section{Results and discussion}

\section{Method development, matrix effects, chromatography, and interferences}

Although MDA-TBA quantification is an easy and inexpensive method, the use of MDA-TBA assays has received wide criticism over the years. The main problem is the lack of sensitivity and specificity, since TBA reacts with a variety of compounds (e.g., amino acids, sugars, aldehydes, albumin, or bilirubin) and generation of interference in colorimetric and fluorimetric MDA-TBA measurements (Janero, 1990; Grotto et al., 2009). Therefore, our high resolution UFLC system with DAD assay for MDA is a useful method to measure the capacity of lipid peroxidation, since it separates the MDA-TBA adduct from interfering compounds.

To avoid the problems caused by the overlap of the MDA-TBA peak and endogenous components present in the assayed biological materials, the TMP standard (the precursor of MDA) was derivatized prior to UFLC separation to obtain a chromophore species with two N-heteroaromatic rings of high molar absorption at longer UV wavelengths (Grotto et al., 2009). Indeed, the occurrence of the absorption maximum close to $530 \pm 1 \mathrm{~nm}$ makes the MDA-TBA derivative almost ideally suited for analysis using UFLC with UV detection (Figure 1A). Moreover, the MDA-TBA adduct in processed MDA standard solution (I) was substantially retained on the
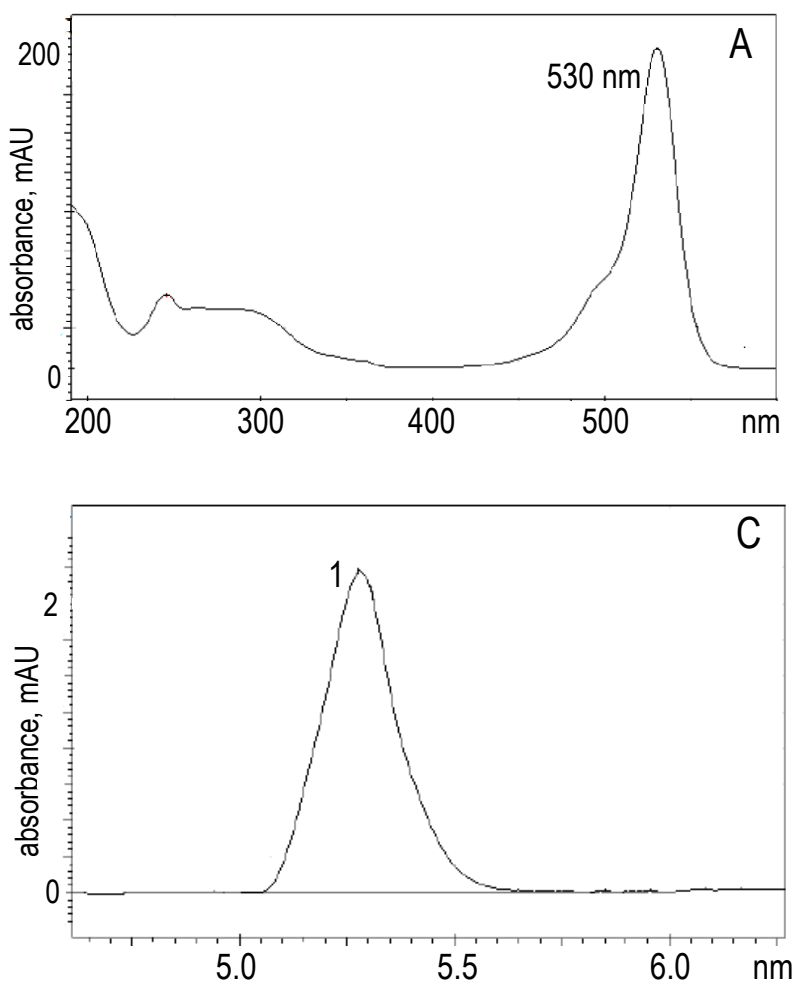

C18-column (Figure 1B). The MDA-TBA adduct peak was eluted at $5.25 \pm 0.05$ min using the binary gradient elution programme (Table 1). The MDATBA adduct peak was absent in the blank sample when the proposed gradient elution programme was used and the photodiode detection set to a UV range from 220 to $620 \mathrm{~nm}$.

As can be seen in Figures 1B and 1C, the optimized processing procedure and the gradient programme (Table 1) utilized acetonitrile in water, which provided a wide range of solvent strengths and excellent baseline stability; multiple injection volumes of examined biological samples were used to better visualize the MDA-TBA adduct peak. Moreover, our optimized chromatographic separation provided excellent baseline stability and allowed precise, accurate, and selective determination of the MDA-TBA derivative in all other assayed biological samples. Indeed, the MDA-TBA adduct possessing high molar absorptivity at longer UV wavelengths (i.e. above $500 \mathrm{~nm}$; Figure 1A) was excellently distinguished from the background fluctuations (Figures 1B and 1C) using an Accucore C18-column and photodiode detection at UV wavelengths $500 \mathrm{~nm}$. On the other hand, monitoring at short UV wavelengths (below $305 \mathrm{~nm}$ ) resulted in higher background fluctuations and noise interference, especially for biological materials, compared with the more selective detection at $530 \mathrm{~nm}$. Moreover, in all assayed biological samples, the close presence of peaks of unidentified species could

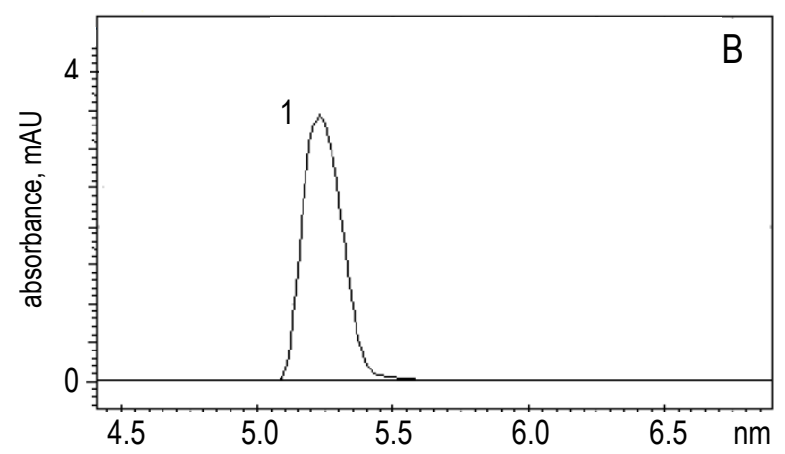

Figure 1. UV spectrum $A$ : the spectrum of the MDA-TBA adduct and its absorbance maximum. Chromatogram B: the MDA-TBA adduct in processed $20 \mu \mathrm{l}$ of the MDA standard solution (the injection volume: $10 \mu l)$. Chromatogram C: the MDA-TBA adduct in processed $100 \mathrm{mg}$ of a liver sample (the injection volume: $45 \mu \mathrm{l})$. AU - the absorbance unit. The peak: 1 - the MDA-TBA adduct. All samples were immediately analysed after processing 
seriously interfere with the precise integration of the MDA-TBA adduct peak when using detection at short wavelengths.

\section{Optimization of derivatization conditions}

The main aim of the current study was to optimize of the conditions of the pre-column derivatization reaction for quantification of MDA as the MDA-TBA adduct in tissue samples and fish oil using reversed phase UFLC with DAD. To achieve the highest possible derivatization yield, the derivatizing procedure should be performed using the smallest possible volumes of saponified biological samples and large excesses of TBA. Previous studies documented that the maximum yield of the derivatization reaction is obtained in 60 min at $95^{\circ} \mathrm{C}-100^{\circ} \mathrm{C}$ (Tarladgis and Watts, 1960) and the reaction rate is faster under acid conditions (Ohkawa and Ohishi, 1979). Considering the above, the derivatizing procedure for MDA in the TMP standards and all assayed biological materials was performed in a water bath at $95^{\circ} \mathrm{C}$ for $60 \mathrm{~min}$. Moreover, the derivatization of MDA in the TMP standards and biological samples was performed in solutions containing about $13.3 \%$ TCA (at $\mathrm{pH} \approx 2$ ). Antioxidants can be used to prevent further formation of MDA during the assay; 2,6-ditert-butyl-p-cresol (BHT) is one of the most widely used antioxidants (Hong et al., 2000; Pilz et al., 2000; Czauderna and Kowalczyk, 2001; Grotto et al., 2009). Nonetheless, Karatas et al. (2002) did not find any differences between the concentrations of the MDA-TBA adduct in processed samples with and without BHT. Therefore, some authors (Lawlor et al., 2000; Karatas et al., 2002; Korchazhkina et al., 2003) do not add BHT to processed biological materials or standard MDA solutions. Considering the above, we developed a simple method for MDATBA analysis in acidic solutions without BHT.

\section{Interference and matrix effects}

Based on the above systematic optimization of the conditions of acid hydrolysis and derivatization, the improved method for MDA-TBA determination in biological materials was applied to chicken liver, muscles and adipose tissue, and to lard and fish oil. As can be seen from the results summarized in Table 2, our chromatographic method offered satisfactory linearity between the concentration of the MDA-TBA adduct and the mass of processed adipose tissue or fish oil. So, these results documented that endogenous components in adipose tissue and fish oil did not affect the yield of MDA-TBA adduct formation. The concentrations of the MDA-TBA adduct were, in fact,

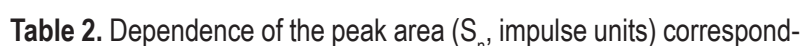
ing to the MDA-TBA adduct in assayed biological materials upon the mass of processed biological materials ${ }^{\mathrm{a}}$

\begin{tabular}{lllll}
\hline \multirow{2}{*}{$\begin{array}{l}\text { Biological } \\
\text { materials }\end{array}$} & \multicolumn{5}{c}{ The mass of processed biological materials, mg } \\
\cline { 2 - 6 } & 25 & 50 & 100 & 200 \\
\hline Liver & $1.09 \cdot 10^{5}$ & $1.54 \cdot 10^{5}$ & $2.13 \cdot 10^{5}$ & $2.94 \cdot 10^{5}$ \\
Thigh muscles & $0.70 \cdot 10^{5}$ & $0.87 \cdot 10^{5}$ & $0.85 \cdot 10^{5}$ & $0.93 \cdot 10^{5}$ \\
Breast muscles & $0.59 \cdot 10^{5}$ & $0.79 \cdot 10^{5}$ & $0.78 \cdot 10^{5}$ & $0.45 \cdot 10^{5}$ \\
Storage fat ${ }^{\mathrm{b}, \mathrm{c}}$ & $2.38 \cdot 10^{5}$ & $7.88 \cdot 10^{5}$ & $20.61 \cdot 10^{5}$ & $33.33 \cdot 10^{5 \mathrm{~d}}$ \\
Fish oile & $30.34 \cdot 10^{5}$ & $70.75 \cdot 10^{5}$ & $113.55 \cdot 10^{5}$ & $179.27 \cdot 10^{5 \mathrm{~d}}$ \\
\hline
\end{tabular}

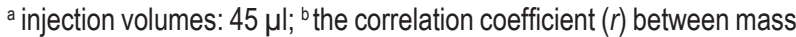
of processed storage fat and $\mathrm{Sn} ; r=0.985 ;{ }^{\circ}$ the intermuscular fat; d formation of trace amounts of red-coloured precipitate was observed in the processed solutions of $200 \mathrm{mg}$ of abdominal fat and fish oil; e the correlation coefficient $(r)$ between mass of processed fish oil and $\mathrm{Sn} ; r=0.977$

well correlated with the mass of processed adipose tissue or fish oil (Table 2). Thus, the results of the performed chromatographic analyses of the MDATBA adduct proved that the applied acid hydrolysis and derivatization with TBA followed by the applied chromatographic system assured satisfactory quantification of derivatized MDA in adipose tissue or fish oil. On the other hand, there was no linear relationship between the concentration of the MDATBA adduct and mass of the processed liver and muscle samples. A possible reason is that TBA is not selective towards MDA, but also reacts with other compounds present in the liver and muscles. Along with other components in the liver and, especially, muscles, proteins may contribute to significant matrix effects. Therefore, it was not valid to create any external calibration (based on standard solutions of MDA) for measuring the MDA-TBA adduct due to the existing matrix effects (especially significant in processed liver and muscle samples). The way to overcome these effects was to use the method of standard additions. Therefore, we conducted experiments in which the same amount of liver and muscle samples were saponified in 20\% TCA followed by derivatization with TBA. Based on the above results (Table 2), about $100 \mathrm{mg}$ of the liver or muscle samples were processed, as $100 \mathrm{mg}$ of these samples provides a relatively satisfactory concentration of the MDA-TBA adduct with relatively little influence of the matrix effects (Table 2). In these experiments, $100 \mathrm{mg}$ of the liver and muscle samples were spiked with various volumes of MDA standard solutions (Table 3). As expected, chromatographic analyses documented that our hydrolysis and derivatization method offered satisfactory linearity of MDA-TBA quantification in the spiked samples of chicken liver, thigh muscles and breast muscles. Therefore, our results demonstrated that the concentration of MDA as the MDA-TBA adduct in protein-rich 
Table 3. Dependence of the peak area $\left(\mathrm{S}_{\mathrm{n}}\right.$, impulse units); ${ }^{\text {a }}$ corresponding to the MDA-TBA adduct in $100 \mathrm{mg}$ of assayed biological materials spiked with the different volumes of the MDA standard solution(I) (derived from TMP)

\begin{tabular}{|c|c|c|c|c|c|c|c|}
\hline \multirow{2}{*}{$\begin{array}{l}\text { Biological } \\
\text { material }\end{array}$} & \multicolumn{6}{|c|}{ Volume of the MDA solution(I) added to $100 \mathrm{mg}$ of processed biological materials } & \multirow{2}{*}{$\begin{array}{l}\text { The correlation } \\
\text { coefficient }(r)^{d}\end{array}$} \\
\hline & $0 \mu \mathrm{l}^{\mathrm{c}}$ & $25 \mu \mathrm{l}$ & $50 \mu \mathrm{l}$ & $75 \mu \mathrm{l}$ & $150 \mu \mathrm{l}$ & $200 \mu \mathrm{l}$ & \\
\hline $\begin{array}{l}\text { Liver } \\
\end{array}$ & $1.14 \cdot 10^{5}$ & $2.19 \cdot 10^{5}$ & $2.96 \cdot 10^{5}$ & $4.81 \cdot 10^{5}$ & $5.20 \cdot 10^{5}$ & $7.43 \cdot 10^{5}$ & 0.9642 \\
\hline Liver (after $24 \mathrm{~h})^{\mathrm{e}}$ & $1.15 \cdot 10^{5}$ & $2.47 \cdot 10^{5}$ & $2.98 \cdot 10^{5}$ & $4.81 \cdot 10^{5}$ & $5.33 \cdot 10^{5}$ & $7.28 \cdot 10^{5}$ & 0.9657 \\
\hline Breast muscles & $0.42 \cdot 10^{5}$ & $2.15 \cdot 10^{5}$ & $2.66 \cdot 10^{5}$ & $3.83 \cdot 10^{5}$ & $6.74 \cdot 10^{5}$ & $8.70 \cdot 10^{5}$ & 0.9970 \\
\hline Thigh muscles & $0.52 \cdot 10^{5}$ & $3.33 \cdot 10^{5}$ & $6.10 \cdot 10^{5}$ & $7.93 \cdot 10^{5}$ & $15.58 \cdot 10^{5}$ & f & 0.9989 \\
\hline
\end{tabular}

a injection volumes: $45 \mu \mathrm{l}$; b the MDA standard solution(I): $10 \mu \mathrm{l}$ of TMP in $100 \mathrm{ml}$ of $20 \%$ aqueous $(\mathrm{m} / \mathrm{m})$ TCA solution; ${ }^{\circ}$ the processed biological material samples without added the MDA standard solution(I); ${ }^{\mathrm{d}}$ the correlation coefficient $(r)$ between volumes of added the MDA standard solution(I) and $\mathrm{S}_{n}$ corresponding to the MDA-TBA adduct in spiked biological samples; ${ }^{\mathrm{e}}$ the processed liver sample were stored for $24 \mathrm{~h}$ in the autosampler at $20^{\circ} \mathrm{C} ;{ }^{f}$ the red-coloured precipitate was formed in the processed thigh muscle samples spiked with $200 \mu$ l of the MDA standard solution(l)

biological materials (e.g., liver or muscles) should be measured using the standard additions method. Moreover, as can be seen from the results summarized in Tables 2 and 3, processing about $100 \mathrm{mg}$ of the liver or muscle samples permitted satisfactory reliability of MDA-TBA determination.

On the other hand, the MDA concentration in biological materials containing negligible concentrations of proteins (e.g., adipose tissue, lard, or fish oil) can be analysed using the external standard calibration method (i.e. derivatized TMP standard solutions).

\section{Reliability of the chromatographic method}

The main analytical problem in the present work was to obtain the highest concentration of the MDATBA adduct in all assayed samples and to achieve selective and sensitive quantification of the MDATBA formed in the processed muscle, liver and adipose tissues, and in lard and fish oil samples. Based on the systematic optimization of the conditions of acid hydrolysis and the derivatization, the highest values of the areas of MDA-TBA peaks were observed when the derivatization was performed at $95^{\circ} \mathrm{C}$ up to $60 \mathrm{~min}$. Indeed, solutions of protein-rich processed biological materials become turbid during derivatization with TBA. Considering the above, derivatization for $60 \mathrm{~min}$ with continuous shaking is especially recommended for such materials. On the other hand, derivatized solutions of adipose tissue, lard, or fish oil are transparent (i.e. without any noticeable red-coloured precipitate).

Another important analytical problem addressed in the current study was to develop a suitable separation technique for the MDA-TBA adduct to avoid the interference of endogenous substances present in all assayed biological materials. Therefore, the separation efficiency of our proposed ultra-fast liquid chromatographic method was assessed by examining the purity $(P u, \%)$ of the MDA-TBA peak in the assayed biological samples.
The peak purity analysis in the MDA standards and all assayed biological samples was performed using the method previously described (Czauderna and Kowalczyk, 2001; Czauderna et al., 2011) as well as using SHIMADZU LC workstation 'LCsolution' software. The results documented that the MDATBA peak for both muscles was pure and free from the influence of closely located signals of unidentified species at wavelengths ranging from 510 to $542 \mathrm{~nm}(P u 95 \%)$. On the other hand, the MDA-TBA peak for liver samples was pure and free from the influence of closely located signals of unidentified species at wavelengths ranging from 520 to $548 \mathrm{~nm}$ $(P u \geq 95 \%)$. Difficulties in the accurate integration of the MDA-TBA peak in muscles and, especially, in liver samples in the shorter UV ranges $(1<510$ $\mathrm{nm}$ and $520 \mathrm{~nm}$, respectively) were responsible for the poor purity of the MDA-TBA peak $(P u<95 \%)$. Indeed, the MDA-TBA peak purities for liver and, in particular, for both muscles, adipose tissue, and fish oil were also satisfactory $(\mathrm{Pu}>95 \%)$ in the shorter $(1<510 \mathrm{~nm})$ and/or longer $(1>548 \mathrm{~nm}) \mathrm{UV}$ ranges ( $P u>95 \%$ for 485 to $555 \mathrm{~nm}$ ) when concentrations of the MDA-TBA adduct in all assayed biological materials were calculated using the height of the MDA-TBA adduct peak. Considering the above, we argue that endogenous species in the liver, especially proteins, decreased MDA-TBA peak purity. On the other hand, the purity of the MDA-TBA peak in adipose tissue, lard and fish oil samples was satisfactory in the UV wavelength range from 480 to $555 \mathrm{~nm}(P u \geq 95 \%)$. In fact, there were no matrix effects (Table 2) or disturbing spectral noises on both sides of the MDA-TBA adduct peak in the assayed adipose tissue, lard and fish oil samples. The simplest explanation is that these biological materials do not contain proteins.

Reproducibility of the present method was assessed by performing replicate injections of processed biological materials (intra-assay coefficients 


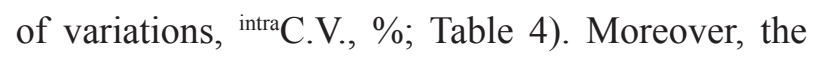
inter-assay coefficients of variations (interC.V., \%) were calculated by using replicate processing aliquots of biological samples (Table 5). The low values of the intra- and inter-assay C.V. as well as the LOD and LOQ values (Table 4) for MDA of biological material samples demonstrated the satisfactory precision and sensitivity of our analytical procedure. The experiments indicated that the areas of the MDA-TBA peaks were practically equal if processed TMP standards and all assayed biological samples were protected from light and stored for $24 \mathrm{~h}$ in an autosampler at $20^{\circ} \mathrm{C}$. On the other hand, storage of processed samples of biological materials for $24 \mathrm{~h}$ at $4^{\circ} \mathrm{C}$ resulted in the formation of a red-coloured

Table 4. Intra coefficients of variation (intra C.V., \%), the limits of detection (LOD) and quantification (LOQ) values derived from determination of the MDA-TBA adduct in processed the MDA standard solutions and biological materials ${ }^{\mathrm{b}}$

\begin{tabular}{llcl}
\hline Sample & C.V., \% & $\begin{array}{l}\text { LOD } \\
\text { picogram }\end{array}$ & $\begin{array}{l}\text { LOQ } \\
\text { picogram }\end{array}$ \\
\hline $\begin{array}{llll}\text { Processed MDA } \\
\quad \text { standards }\end{array}$ b.c & 0.37 & 5.4 & 17.8 \\
Liver & 1.60 & 12.8 & 42.3 \\
Thigh muscles & 0.27 & 6.2 & 20.4 \\
Breast muscles & 0.68 & 6.7 & 22.1 \\
Storage fat & 1.62 & 10.6 & 35.0 \\
Abdominal fat & 1.01 & 9.3 & 30.7 \\
Lard & 3.53 & 10.1 & 33.4 \\
Fish oil & 1.58 & 9.0 & 29.8 \\
\hline
\end{tabular}

a intraC.V. - values based on about $100 \mathrm{mg}$ of processed biological materials, each with seven injections; injection volumes: $40 \mu$; b intra C.V. - values based on processed $25,50,75$ and $150 \mu$ l of freshly prepared MDA solution(I) samples, each with two injections; injection volumes: $45 \mu \mathrm{l}$; ' the linear regression line of MDA-TBA adduct based on processed MDA solution(I) samples: $\mathrm{y}(\mu \mathrm{g})=4 \cdot 10^{-9} \mathrm{Sn}+8 \cdot 10^{-5}$ (the range of MDA concentrations: $24.7-0.386 \mathrm{ng})$; the correlation coefficient $r=0.9999$

Table 5. Inter coefficients of variation (interC.V., \%) derived from determination of the MDA-TBA adduct in processed MDA standard solutions and biological materials ${ }^{a}$

\begin{tabular}{ll}
\hline Sample & ${ }^{\text {interC.V., } \%}$ \\
\hline Processed MDA standard solutions & $1.59^{\mathrm{b}}$ \\
Liver $^{\mathrm{c}}$ & 6.96 \\
Thigh muscles $^{\mathrm{d}}$ & 6.97 \\
Breast muscles $^{\mathrm{e}}$ & 5.85 \\
\hline
\end{tabular}

a interC.V. - values based on liver, thigh and breast muscle samples from nine chickens, each processed biological samples with one injection; injection volumes: $45 \mu \mathrm{l}$; ${ }^{b}$ values based on processed 25,50 , 75 and $150 \mu$ lof freshly prepared MDA solution(I) samples, repeated two times (processing and injection); injection volumes: $45 \mu \mathrm{l} ;{ }^{\circ}$ the average MDA concentration in the processed fresh liver samples $(n=9): 206 \mu \mathrm{g} \cdot \mathrm{g}^{-1} ; \mathrm{d}$ the average MDA concentration in the processed fresh thigh muscle samples $(n=9): 163 \mu \mathrm{g} \cdot \mathrm{g}^{-1}$; e the average MDA concentration in the processed fresh breast muscle samples $(n=9)$ : $154 \mu \mathrm{g} \cdot \mathrm{g}^{-1}$ precipitate. Consequently, the MDA-TBA peak area decreased in processed biological materials (especially in samples of liver and both muscles) stored at $4{ }^{\circ} \mathrm{C}$ in an autosampler for $24 \mathrm{~h}$.

The proposed procedure allowed accurate, sensitive and precise chromatographic evaluation of MDA as a biomarker for oxidative stress in animals and oxidative stability biological materials. We suggest that external calibration (based on the processed MDA standard solutions) should be used for measuring the concentration of the MDA-TBA adduct in adipose tissues, lard and fish oil, due to absence of matrix effects. Considering the above, we also suggest that external calibration can also be applied for quantification of MDA in plant oils (e.g., rapeseed, linseed or sunflower oils). On the other hand, it was not valid to create any external calibrations for measuring MDA in biological materials rich in proteins, due to the existing matrix effects. The way to overcome this problem was to use the method of standard additions. Thus, the concentration of the MDA-TBA adduct in assayed protein-rich biological samples should be calculated as the difference between the concentration of MDA-TBA measured in spiked and non-spiked samples of the same mass and specimen and the known concentration of the spike. For liver or muscle samples containing similar concentrations and profiles of proteins (i.e. similar matrix effects), we suggest the use of external calibration based on MDA standard solutions added to the same mass (e.g., about $100 \mathrm{mg}$ ) of liver or muscles (i.e. the same specimen) for measuring the MDA concentration of assayed biological materials. Obviously, the linearity of the external calibration based on the MDA standard solutions added to the same mass of biological material documented that matrix effects were not a problem for the same type of assayed biological materials (e.g., liver, muscles, heart, or spleen).

\section{Conclusions}

The presented ultra-fast liquid chromatography (UFLC) method preceded by improved derivatization of malondialdehyde with 2-thiobarbituric acid can be suitable for routine analysis of oxidative stress in tissues of farm animals, as well as the oxidative stability of biological materials, including food and feed.

The present UFLC method is also suitable for laboratories equipped with HPLC. 


\section{Acknowledgements}

The research was realized within the project 'BIOFOOD - innovative, functional products of animal origin' No. POIG.01.01.02-014-090/09 cofinanced by the European Union from the European Regional Development Fund within the Innovative Economy Operational Programme 2007-2013.

\section{References}

Baldeiras I., Santana I., Proenca M.T., Garrucho M.H., Pascoal R., Rodrigues A., Duro D., Oliveira C.R., 2010. Oxidative damage and progression to Alzheimer's disease in patients with mild cognitive impairment. J. Alzheimers Dis. 21, 1165-1177

Czauderna M., Kowalczyk J., 2001. Separation of some mono-, diand tri-unsaturated fatty acids containing 18 carbon atoms by high-performance liquid chromatography and photodiode array detection. J. Chromatogr. B 760, 165-178

Czauderna M., Kowalczyk J., Marounek M., 2011. The simple and sensitive measurement of malondialdehyde in selected specimens of biological origin and some feed by reversed phase high performance liquid chromatography. J. Chromatogr. B, $879,2251-2258$

Dizdaroglu M., Jaruga P., Birincioglu M., Rodriguez H., 2002. Free radical-induced damage to DNA: mechanisms and measurement. Free Radical Biol. Med. 32, 1102-1115

Esterbauer H., Schaur R.J., H. Zollner H., 1991. Chemistry and biochemistry of 4- hydroxyl-nonenal, malonaldehyde and related aldehydes. Free Radical Biol. Med. 11, 81-128

Grotto D., Santa Maria L.D, Valentini J., Paniz C., Schmitt G., Garcia S.C., Pomblum V.J., Rocha J.B.T., Farina M., 2009. Importance of the lipid peroxidation biomarkers and methodological aspects for malondialdehyde quantification. Quim. Nova 32,169-174

Hong Y., Yeh S., Chang C., Hu M., 2000. Total plasma malondialdehyde levels in 16 Taiwanese college students determined by various thiobarbituric acid tests and an improved high-performance liquid chromatography-based method. Clin. Biochem. 33, 619-625

Janero D.R., 1990. Malondialdehyde and thiobarbituric acid-reactivity as diagnostic indices of lipid peroxidation and peroxidative tissue injury. Free Radical Biol. Med. 9, 515-540
Karatas F., Karatepe M., Baysar A., 2002. Determination of free malondialdehyde in human serum by high-performance liquid chromatography. Anal. Biochem. 311, 76-79

Kong Q., Lin C.L., 2010. Oxidative damage to RNA: mechanisms, consequences, and diseases. Cell. Mol. Life Sci. 67, 1817-1829

Korchazhkina O., Exley C., Spencer S.A., 2003. Measurement by reversed-phase high-perfor-mance liquid chromatography of malondialdehyde in normal human urine following derivatisation with 2,4-dinitrophenylhydrazine. J. Chromatogr. B 794, 353-362

Lawlor J.B., Sheehy P.J.A., Kerry J.P., Buckley D.J., Morrissey P.A., 2000. Measuring oxidative stability of beef muscles obtained from animals supplemented with vitamin $E$ using conventional and derivative spectrophotometry. J. Food Sci. 65, 1138-1141

Levine R.L., Williams J.A., Stadtman E.R., Shacter E., 1994. Carbonyl assays for determination of oxidatively modified proteins. Methods Enzymol. 233, 346-357

Lykkesfeldt J., 2001. Determination of malondialdehyde as dithiobarbituric acid adduct in biological samples by HPLC with fluorescence detection: comparison with ultraviolet-visible spectrophotometry. Clin. Chem. 47, 1725-1727

Mateos R., Bravo L., 2007. Chromatographic and electrophoretic methods for the analysis of biomarkers of oxidative damage to macromolecules (DNA, lipids, and proteins). J. Sep. Sci. 30, 175-191

Nielsen F., Mikkelsen B.B., Nielsen J.B., Andersen H.R., Grandjean P., 1997. Plasma malondialdehyde as biomarker for oxidative stress: reference interval and effects of life-style factors. Clin. Chem. 43, 1209-1214

Ohkawa H., Ohishi N., 1979. Assay for lipid peroxides in animal tissues by thiobarbituric acid reaction. Anal. Biochem. 95, 351-358

Oter S., Jin S., Cucullo L., Dorman H.J.D., 2012. Oxidants and antioxidants: friends or foes? Oxid. Antioxid. Med. Sci. 1, 1-4

Pilz J., Meineke I., Gleiter H.C., 2000. Measurement of free and bound malondialdehyde in plasma by high-performance liquid chromatography as the 2,4-dinitrophenylhydrazine derivative. J. Chromatogr. B 742, 315-325

Tarladgis B.G., Watts B.M., 1960. Malonaldehyde production during the controlled oxidation of pure unsaturated fatty acids. $\mathrm{J}$. Amer. Oil Chem. Soc. 37, 403-407

Wong S.H.Y., Knight J.A., Hopfer S.M., Zaharia O., Leach C.N., Sunderman F.W., 1987. Lipoperoxides in plasma as measured by liquid-chromatographic separation of malondialdehydethiobarbituric acid adduct. Clin. Chem. 33, 214-220 